\title{
Inscrutable medicines and marginal markets: tackling substandard veterinary drugs in Nigeria
}

Pete Kingsley

\begin{abstract}
Background: Substandard drugs have long been a major human health problem in developing countries, and similar issues also beset the veterinary drug industry. Although less immediately costly to human life, the failure of veterinary treatment can be devastating for pastoralist livelihoods.

Research on this problem has tended to be scientific, focussing on the prevalence and potential consequences of poor-quality products. In contrast, the social processes by which such products are traded and used have received far less scholarly attention. This study takes the case of animal African trypanosomiasis, one of Africa's most important cattle diseases, and uses interviews and focus groups to follow drugs as they pass through the supply chain from importers and distributors to vendors and customers.

Results: Each set of actors uses different strategies to mitigate the risks of substandard drugs. For instance, pastoralists experiment carefully with suspect products before using them across their herds, whilst drug vendors and cattle owners try to invest in relationships with one another. These efforts of building reputation and trust, however, are hampered by the elusive nature of substandard drugs. Drug quality is impossible to gauge visually, and the treatment failure that substandard drugs can produce also has other causes, confusing the issue.

Conclusion: Nigerian regulators are beginning to address this problem. A keen understanding of the strengths (efficiency and reach into rural areas) and weaknesses (difficulties in identifying fake and substandard products) of the veterinary drug marketplace should underpin their response to this issue.
\end{abstract}

Keywords: Substandard drugs; Fake drugs; Fulani; Nigeria; Animal health; Informal markets; Regulation

\section{Background}

In a focus group held in a village in Plateau State in Nigeria's middle belt, livestock owners reflected on the quality of veterinary drugs available to them. In particular, they were concerned about drugs to treat the cattle disease trypanosomiasis:

'Before the drugs used to be strong, now you can't predict which ones will work' (interview with a Fulani cattle owner in his 40s, in Maiyanga, Plateau State, 29 April 2014)

Cattle owners went on to discuss their disappointment with the veterinary drugs they bought from nearby towns or the small shop in the neighbouring village. There was a consensus that over the last ten years, but especially over

Correspondence: pete.kingsley@ed.ac.uk

Centre of African Studies, The University of Edinburgh, Edinburgh, UK the last five, poor-quality products had become increasingly commonplace and that identifying efficacious drugs had become a lottery.

These cattle owners are the endpoint of Nigeria's veterinary drug supply chain. At the opposite end of this chain are the importers and manufacturers of veterinary drugs, many located in Lagos, $700 \mathrm{~km}$ away. The CEO of one of Nigeria's largest importers reflected that drugs to treat trypanosomiasis, once a mainstay of his business, were being swamped by dubious new products:

'They are the largest selling class of cattle drugs in Nigeria. Trypanocides used to form a large part of our turnover, but in the last three or four years, it has plunged. And in the last five years, all sorts of trypanocides have come into the country, from Asian countries, China, India, Egypt, The Middle East, all sorts of trypanocides, very cheap, we don't know whether they are effective or not.' (interview in Lagos, 15 April 2014) 
Despite their very different cultural and geographical positions, cattle owners and senior industry figures described similar concerns about a sharp rise in the presence of dubious products in this supply chain. This paper explores this apparent recent escalation in veterinary drug quality problems by examining how such drugs are bought and sold.

Whilst almost all parties agree that a long-standing problem has metastasised into a major crisis over the last few years, there is a marked lack of clarity regarding the scale and origins of this problem. Furthermore, different actors conceive the problem in different ways, which in turn emphasises different potential remedies. Scientific and veterinary research, often in the form of small-scale exploratory studies, has identified the presence of poorquality veterinary products (Wanyangu et al. 1996; Van Wyk et al. 1997; Teko-Agbo et al. 2008; Gberindyer et al. 2014). Other research has described in structural terms the veterinary medicine industries in various African countries (Grasswitz et al. 2004) and the legal frameworks for regulating those sectors (Kané 2008).

However, remarkably little attention has been paid to the actual workings of veterinary supply chains - that is, social ties forged in negotiation, trust and self-interest which are required to move medicines between places and people. As the state has largely withdrawn from the provision of veterinary services, actors at all stages of the supply chain have been forced to adapt. Like many other Nigerian industries, in part this means coping with the lack of a state that can reliably enforce contracts and the consequent low levels of trust between actors in different stages of the supply chain - a phenomenon long discussed in African settings (e.g. Widner and Mundt 1998; Zak and Knack 2001). Such situations can be especially acute for livestock owners who are likely to be involved in trading patterns involving mobile vendors and buyers, as well as 'long distances, and delayed payment in the absence of adequate financial institutions' (van Ufford and Zaal 2004: 121).

Collating perceptions of drug quality from various locations in the supply chain emphasises the multiplicity of the problem and the different foci of various actors. Global pharmaceutical companies, international importers and distributors and, to a lesser extent, regional wholesalers generally frame the drug quality issue in terms of criminality and law enforcement - a problem is rogue products and providers, requiring a solution of more active regulation. These providers, however, along with regional wholesalers and local vendors of drugs also suggest that a major problem is the poor veterinary practices of the Fulani, the ethnic group who own the vast majority of Nigeria's cattle ${ }^{\mathrm{a}}$. It is alleged that these cattle owners incorrectly administer drugs in a variety of ways causing treatment failures that are difficult to distinguish from those caused by poor drug quality.

Interviews and focus groups with cattle owners confirm that non-standard veterinary practices are commonplace. However, far from being ignorant and backward, as much derogatory rhetoric from elsewhere in the drug supply chain (and more broadly across urban and southern Nigeria) implies, the Fulani are fully aware of problems with drug quality and pursue active and innovative strategies to mitigate the financial and health risks involved. In a sense, the substandard drug problem destabilises conventional assumptions about veterinary expertise. Parts of the pharmaceutical industry may well be producing incorrectly formulated drugs, whilst pockets of informal and uncertified veterinary knowledge can be found in unexpected places.

Reflecting on the nature of the veterinary drug supply chain has a number of implications. An entire supply chain has emerged that is unregulated, informal, yet lucrative, highly organised and an important part of one of Nigeria's most important industries. Given the scale of this industry, an enforcement-based solution to drug quality is likely to be difficult to implement. Instead, the problem needs to be understood as three interrelated issues - the emergence of dubious products into the marketplace, the decline (or even collapse) of formal veterinary services in rural areas and the structural neglect of cattle owners.

There are a number of apparently straightforward strategies for securing better drug quality that seem difficult to pursue or sustain. Cattle owners could pool their resources, informally or as part of cooperatives, to buy drugs from more distant but reputable vendors. Drug vendors could be trained to identify fake and counterfeit drugs and to store their products correctly. National authorities are belatedly investigating the issue - but could have done so vigorously at a much earlier date. The various reasons for these missed opportunities - particularly regarding the difficulty in building a reputation for selling good-quality products when that quality is hard to prove are discussed.

The failure to develop a more secure supply chain reflects different priorities in tackling the problem. For pharmaceutical companies, the problem is the economic threat posed by counterfeit and substandard products of all kinds. For cattle owners, however, the problem of drug quality is one part of the much broader challenge of securing animal health. A deeper issue, however, is the political and cultural marginality of cattle owners in general, but particularly the Fulani people. The lack of government attention to these issues even as campaigns against other counterfeit products have been successful reflects the low priority given to these often-impoverished, rural-dwelling cattle owners. This is evident generally in a 
slow-moving policy process at the federal level, but also in specific places like Plateau State where contentious political disputes further hamper the ability of the Fulani to seek government assistance. Thus, the issue of drug quality is driven by inadequate veterinary practices and unscrupulous vendors and manufacturers, but is sustained by a general disconnection and disdain for the Fulani, which is palpable in many areas of Nigerian life.

This paper begins by reviewing previous attempts to tackle substandard drugs, particularly for human drugs where efforts have been more intensive. It then introduces a methodology for exploring this ambiguous and often clandestine problem. The empirical material presented begins with an institutional history of veterinary drug control in Nigeria, before presenting the findings of interviews and focus groups with suppliers, distributors, vendors and customers. It concludes by reflecting on the implications of these findings - both for understanding the functioning of Nigerian markets and for potential remedies to the problem.

\section{Substandard drugs}

In treatment for humans, falsified and substandard drugs have for some time been seen as a major public health problem, particularly in low-income countries (Fernandez et al. 2008). A broad range of actors, from the WHO and transnational pharmaceutical companies to national and local distributors, regulatory authorities, physicians, pharmacists and patients, have been enrolled in tackling this issue (Dégardin et al. 2014). However, clarifying the definition, nature and scale of the problem has proved to be a challenging and controversial task.

The WHO resolved to address the issue of 'falsely labelled, spurious, counterfeited or substandard' medicines in 1988 (Burci 2013), which evolved into the current category of 'substandard/spurious/falsely-labelled/falsified/ counterfeit medical products' (WHO 2011). As this unwieldy definition implies, it is an expansive category that covers a broad spectrum of possibilities ranging from malicious criminality (such as the selling of outright fakes or even toxic products) to unintended quality issues that emerge in manufacturing, storage and distribution.

A particularly important definitional issue with substandard drugs has been the status of generic drugs. Pharmaceutical companies have been accused of conflating the problem of substandard products with the use of generics (Shukla and Sangal 2009), that is, copies of 'brand name' drugs that are no longer protected by patents. Some generics may well be of poor quality - a fact that brand name pharmaceutical companies are keen to point out - but many generics are of comparable quality with their 'brand name' counterparts (Newton et al. 2011). By muddying the waters in this way, pharmaceutical companies have been accused of hijacking efforts to tackle a public health problem in order to protect their own products (Clift 2010).

Thus, pharmaceutical companies and regulators in developing countries tend to approach the substandard drug problem in ways that overlap, but also differ significantly. And, as the WHO argues:

\section{'The absence of a universally accepted definition not only makes information exchange between countries very difficult but it also limits the ability to understand the true extent of the problem at global level. ${ }^{\mathrm{b}}$}

Regulators may equate 'substandard and fake' with 'unregistered and ineffective', whilst pharmaceutical companies may emphasise 'in violation of intellectual property rules and ineffective'. This tension between commercial and public health approaches to the drug quality issues in part frames the options available to Nigerian regulators - a subject discussed further in the conclusion of this paper.

As well as definitional issues, there are also serious shortcomings in the evidence base regarding substandard drugs. Despite broad agreement that drug quality issues are a major problem, 'there is still surprisingly little basic research data to support widely repeated claims about the prevalence of drug counterfeiting' (Seear et al. 2011: 488). For counterfeiting specifically, the clandestine and criminal nature of some of the actors involved hampers research. For the broader problem of drug quality, the cost and technical difficulty of drug testing make regular, widespread surveys of the problem difficult. A systematic review notes that many studies of substandard drug prevalence have been highly limited in their scope or subject to less-than-ideal sampling methods (Almuzaini et al. 2013). Notwithstanding these shortcomings, what research that has been conducted confirms the serious nature of the problem. One review of human drugs suggests that globally 'up to $15 \%$ of all sold drugs are fake' (Cockburn et al. 2005), whilst some especially alarming studies have described markets in which more than half of all anti-malarial drugs on sale contain no active ingredient (Dondorp et al. 2004).

In many ways, the veterinary drug sector faces similar problems but as a research topic has been even more neglected. The International Federation for Animal Health reports that the trade in unregistered and substandard veterinary drugs is worth $\$ 400$ million annually - a size similar to the legitimate market (FAO 2012). Other disease-specific studies have warned of the availability of fake products (e.g. Melaku and Birasa 2013), whilst other research has subjected samples purchased to laboratory testing (e.g. Chaka et al. 2009; Gberindyer et al. 2014). Importantly, substandard products which contain some active ingredient but at a lower-than-specified level 'are 
not only less effective when used by farmers, but also greatly increase the risk of drug resistance developing' (Geerts et al. 2001: 28; see also Waller et al. 1996: 184). As well as the direct harm caused by poor drug quality and treatment failure, many industry actors interviewed emphasised that a large market for substandard or fake products acted as a major disincentive for the development of new products. A preponderance of fake and substandard products might even imperil the continued manufacturing of genuine drugs, should those 'brand name' drugs continue to lose ground in the marketplace.

Whilst human health has understandably been prioritised in interventions to address drug quality issues, veterinary drugs are a vital part in some of Africa's most important industries. Large numbers of Africans rear cattle as a key part of their livelihood, and many more own animals as a supplement to their main household income (Thornton et al. 2002). As is well known, cattle often perform important additional social and economic functions beyond the meat and dairy products they provide, such as acting as forms of savings, insurance and draught power (e.g. McPeak et al. 2011: 10-43).

\section{Trypanosomiasis and Nigeria}

To explore these issues, this paper focusses on a specific country, Nigeria, and a specific cattle disease, animal African trypanosomiasis. Nigeria is an important case study in various ways. As well as being Africa's most populous nation, it has a large cattle industry ${ }^{c}$, and most especially, it has often been considered to be 'ground zero' in the human drug quality problem. Particularly in the late 1990s and early 2000s, there was great concern at the extremely widespread drug quality problem (e.g. Erhun et al. 2001). Whilst some raised the alarm in the 1990s (Alubo 1994), the issue of drug quality only received sustained government attention following the return to democracy in 1999. As we shall see, quality problems with veterinary drugs emerged over a similar period, though they have received far less official attention.

The National Agency for Food, Drug Administration and Control (NAFDAC) rose to promise as the agency mandated to tackle this emerging problem, particularly under the tenure of its former Director-General Dora Akunyili (2001 to 2009). Indeed, NAFDAC has become a celebrated 'success story' following vigorous enforcement and public awareness campaigns (e.g. Raufu 2006). NAFDAC, however, has only recently begun to address the veterinary drug sector systematically.

African trypanosomiasis is a parasitic infectious disease present across a large area of West, Central and Eastern Africa, a 'tsetse belt' that is named after the insect that is the parasite's primary vector. There are a number of subtypes of trypanosomiasis, one of which primarily affects humans (Trypanosoma brucei gambiense) and another
(Trypanosoma brucei rhodesiense) that is zoonotic (crossing between humans and animals). Referred to as 'sleeping sickness' when present in humans, human African trypanosomiasis poses a major public health threat in countries such as Uganda and the Democratic Republic of Congo. Other countries such as Tanzania, Ethiopia, Kenya and Nigeria have largely controlled trypanosomiasis as a threat to human health, but it remains a major livestock disease (sometimes known as 'nagana' or 'sammoré'), affecting cattle especially, but also goats, sheep, camels and various other mammals.

Trypanosomiasis exacts a major economic burden on livestock production as the parasite kills animals or retards their growth and reproduction. Budd (1999) suggested that such losses may be valued at as much as $\$ 4.5$ billion per annum across Africa. Although there is no vaccine, a number of drugs, known as trypanocides, offer effective prophylactic or curative treatment. These trypanocides 'are probably the most commonly used veterinary products in sub-Saharan Africa' (Geerts et al. 2001: 25), an impression affirmed by distributors in Nigeria. Nonetheless, trypanosomiasis and other livestock diseases are far from the only pressing threats to pastoralist livelihoods in Northern Nigeria.

Since 2001, there has been a series of violent clashes in Plateau State in both urban and rural areas. Although such violence is often interpreted as stemming from tension between Islamic Fulani pastoralists and Christian agriculturalists, as Adam Higazi shows, this is only a partial explanation at best. Instead, the violence emerges from a complex interplay of factors, including 'religion, ethnicity and politics; socio-economic disparities and indigeneity; education; political leadership and 'the youth'; land and cattle' (Higazi 2013: 3).

In 2010, during one such episode of violence, Dr. Ita Umoh, a veterinary doctor, was killed during violence in Vom, Plateau State (the home of the National Institute for Veterinary Research). This event underscored the increasing difficulty of working safely in rural areas of Plateau State. Various vets currently or formerly based in Vom (interviews in April, May and October 2014) pointed out that whilst the high value of cattle meant that livestock veterinary work remained potentially very profitable, security concerns had led to a drastic reduction in the number of qualified veterinarians working in rural areas. Whilst a fuller account of violence in Plateau State is beyond the scope of this article (see Okello et al. 2014 for related discussion), it is important to recognise how these clashes are both a threat to Fulani livelihoods and an aggravating factor in their already-fraught relationship with the Nigerian government, particularly at state and local levels.

\section{Methodology}

Important research is currently being carried out by the Global Alliance for Livestock Veterinary Medicines 
(GALVmed) and the EU-funded research consortium TRYRAC to test the quality of trypanocides available in various African marketplaces. This research aims to complement these laboratory-based studies of the substandard drug problem. In doing so, it aims to draw out a series of structural and social issues that tend to be sidelined in such studies. In particular, this means describing the particularities of the Nigerian markets and livestock owners and describing more generally the means by which drugs are bought and sold. Following van der Geest et al. (1996), this research adopts producing a 'biography of pharmaceuticals', that is, to trace how a particular class of drugs passes through each stage of a supply chain to the end user.

In April and May 2014, interviews were conducted with key actors at each step of the distribution chain - from international importers, manufacturers and distributors who trade in multi-million dollar quantities to rural cattle owners who buy veterinary trypanocides from a rural vendor in two or three $\$ 3$ packets at a time. Specifically, this involved meetings with importers, distributors, vendors of various kinds, veterinarians, regulatory officials and customers in Lagos, Abuja, Kaduna, Jos, Vom, Zaria and Kano, as well as various villages and small towns in the Bokkos Local Government Area in Plateau State. This involved 32 interviews in total.

All participants were asked about their opinions and experiences with trypanosomiasis drug quality problems. For instance, drug vendors were asked about the steps they took to procure good-quality products, whether their customers had complained about the drugs they sold, which products their customers preferred and why, and so on. Similarly, cattle owners were asked about which trypanocides they preferred and about the strategies they used to mitigate the economic and animal health risks of poorquality drugs. Interviews with end users were supplemented with two focus groups, each held in the Bokkos Local Government Area with groups of around 12 herders. Most of the meetings were conducted in English, though some interviews and the focus group took place in Hausa ${ }^{\mathrm{d}}$. The informed consent of all participants was secured. Many of the issues discussed are sensitive, for example, when interviewees are invited to comment on the trustworthiness of their competitors or business partners. For that reason, I have tried to balance explaining where people work and who they represent, whilst preserving their anonymity.

The goal is not to systematically survey the market (though this would be a viable area for future investigation), nor is it to scientifically examine the drugs themselves (an important step, but difficult to do at any scale whilst the cost of testing the drugs remains high). Nor is the goal to investigate and uncover the transnational sources and flows of at least some problematic drugs (again, a viable but separate project). Instead, I offer a 'biographical approach' which aims to 'study of transactions and meanings of pharmaceuticals in diverse social settings' (1996: 153; see also Harper et al. 2011). Through understanding the processes through which drugs are assessed, bought and sold, issues of judgement, expertise and above all trust are foregrounded as crucial parts of the supply chain.

A supply chain that crosses such diverse social and geographical terrain, however, can only ever be studied in part. I set out some salient contextual features that enhance or attenuate the relationships between actors, but these should not be assumed to be universal throughout the varied contexts in which veterinary drugs are bought and sold in Nigeria. Instead, they are intended to be examples of the broad range of social processes that regulate drug transactions. This paper argues, therefore, that describing these social processes is crucial for understanding the nature of the drug quality problem, especially as they are usually concealed behind the schematic terms 'supply chain' or 'market'.

\section{The history of veterinary drug control in Nigeria}

This paper argues that veterinary care practices have emerged and continue in conditions of state abandonment. Interviews with retired officials and researchers underscored that this abandonment was not always the case. Lyons (2002) refers to trypanosomiasis as a colonial disease, emphasising that controlling the disease was a major imperial priority (see also Tilley 2004). Despite various difficulties, particularly in terms of staffing, for institutions transitioning to national rather than colonial status following independence, many viewed the 1960s and 1970s as a 'golden age' for tackling trypanosomiasis. Not only were widespread efforts to control the tsetse fly, the primary vector of trypanosomiasis, effectively carried out, government veterinary services were able to offer a significant range of services in rural areas. For example, the precolonial and colonial system of taxation of the Fulani, known as jangali, involved the government provision of veterinary services as part of an implicit quid pro quo (Adebayo 1995).

Respondents explained that whilst some veterinary drugs were bought and used privately, until the 1980s, most passed through an essentially closed state-administered system that largely secured the authenticity and quality of products. Cattle owners do not always recall the era prior to the 1980s fondly ${ }^{\mathrm{e}}$, as some recall that government veterinarians would sometimes supply drugs and vaccines on credit, only to seize the animals when bills went unpaid. Nonetheless, cattle owners in the focus group participants agreed that treatment was more reliable and cheaper in those decades, as a tightly controlled and subsidised supply chain left little room for substandard products. 
However, by the late 1960s and especially in the 1980s, this system of state veterinary drug administration began to collapse, both in Nigeria and elsewhere in Africa (Leonard 1993). Perhaps ironically, the number of qualified veterinarians in Nigeria actually increased significantly during this period. However, as in much of Africa, such vets became less likely to work in rural areas or in the public sector, instead preferring urban, private practice focussing on small animals and poultry (as discussed in interviews; see also Babalobi 2007).

As the state abruptly withdrew from provision and offered little in the way of regulation, the private sector expanded in various guises. Some fake or counterfeit products began to emerge in the late 1980s and 1990s. A number of interviewees recalled the practice of simulating the orange colour of Novidium ${ }^{\mathrm{f}}$ with the soft drink Fanta, whilst others described a process in which the caps worn by Hausa men ('dara') would be dipped in water to extract their dye, again to manufacture fake products of the appropriate colour.

Despite the establishment of NAFDAC in 1993, the Federal Ministry of Agriculture continued to be theoretically responsible for the regulation of veterinary products in the 1990s. One senior official recalled how plans were made for regional inspection teams and checkpoints, but resource constraints prevented any real intervention. Many interviews also noted that tackling the significant outbreak of rinderpest and contagious bovine pleuropneumonia in the late 1980 s and early 1990 s was a major drain on government resources. As one former official recalled:

'the publically authorised veterinarians were not available to give the routine treatment for [trypanosomiasis]. The quacks and even the Fulani man took the syringe himself (interview with a retired Ministry of Agriculture civil servant, conducted in Zaria, 24 April 2014)

Drug quality issues in Nigeria therefore are enabled by a series of domestic factors, with the deregulation of the veterinary drug sector and the emergence of some fake and falsified products over the last 30 years or so. However, all the respondents in this study reported that these long-standing fake or counterfeit products were now less common than a range of generic products which have rapidly penetrated the market over the last ten years and especially in the last five:

'See them coming from India, China everywhere - they are a big flood' (interview, manager of a large regional distributor based in Kaduna, 23 April 2014)

In the continuing absence of widespread testing of veterinary drugs, the quality of these generic products remains frustratingly uncertain. The consensus, however, was that such generics were by no means universally poor, but rather uneven and unpredictable in quality.

By 2011, the Nigerian Veterinary Medical Association (NVMA) and other veterinary organisations were raising the alarm and demanding action. In particular, they insisted that NAFDAC (which they noted already had both the necessary expertise and a legal mandate ${ }^{\mathrm{g}}$ ) intervene. In April 2013, NAFDAC formed a Veterinary Medicines and Allied Products directorate, based in Yaba, Lagos. Officers at the new directorate reported that they were conducting a baseline study to determine the prevalence of substandard or unregistered products, due to be completed in 2014. This exercise coincides with a moratorium or 'grace period' during which enforcement will be postponed as information is gathered.

Several officers at the new department reported that in addition to veterinary drugs, unsafe pesticides (with their potential to enter the human food chain) were seen as a particular priority. Many actors in the supply chain were pleased that NAFDAC was intervening. Several mentioned that the employment of a significant number of veterinarians (the lack of whom was a long-standing gripe amongst Nigerian veterinary associations) would be an important requirement.

Interviewees proposed various reasons why NAFDAC had taken so long to become involved in this area, often relating to internal and inter-agency politics and the slow-moving nature of Nigeria's bureaucracy. The major impetus for change appears to have been pressure from bodies such as the NVMA, rather than lobbying from cattle owners themselves, confirming other research suggesting professional associations often act as important brokers in Nigeria (Kingsley 2014). What is clear, however, is that at least for two decades, a major threat to the livelihoods of livestock owners has largely been neglected by the Federal government.

\section{Drug quality - different understandings, different strategies}

Despite clear agreement about the increased prevalence of poor-quality drugs and the absence or at least sluggishness of state assistance, other aspects of the substandard drug problem are more controversial. In particular, the exact nature of this problem is difficult, as it is experienced differently from different social, structural and geographical locations. From the point of view of cattle owners, the problem is clear: treatment failure. One pastoralist in his mid-20s who was often sent by his family to purchase drugs reported: 'You may buy the drug from [a nearby village shop] but after two or three weeks can see nothing has happened' (interview in Bokkos town, Plateau State, 30 April 2014).

For importers, distributors and vendors, the problem is seen in economic terms - the CEO of one major distributor 
reported that he had lost $25 \%$ to $35 \%$ of his trypanocide business over the last four years (interview, Lagos, 15 April). Other regional distributors who dealt primarily in well-known brand names reported similar losses.

There are also disagreements in the causes of the problem. Some argue that the ignorance of the Fulani is to blame. As one distributor said:

\section{'They buy the wrong products, they buy poor quality} ones, they use them incorrectly. They are really hurting their own animals.' (drug distributor and vendor, Kano, 28 April 2014)

Many also blamed the Nigerian government for 'just standing by' whilst dubious generic products filled the marketplace. Others, particularly those with veterinary training, emphasised the issue of underdosing.

Regardless of where blame was apportioned, vendors nonetheless used various strategies to build trust with particular customers. They said that a common strategy was to offer a customer a small amount of credit to buy products (often just two or three sachets of trypanocide, sold at N400 (£1.50) each) for the customer to test the product. This act of placing faith in the customer to return and pay was both a gesture of goodwill and demonstration of confidence in the products sold. When such debts were repaid, vendors reported that they would gradually offer customers higher levels of credit, contingent on further repayments. Perhaps because of the nature of cattle ownership - with much wealth held in the relatively illiquid form of livestock - the use of credit to build relationships of trust was particularly important.

In short, various traders and distributors see the drug quality problem as a set of separate but overlapping issues. Treatment failure reported by their disgruntled customers and a rash of suspicious new products are evidence of shortcomings in both drug quality and veterinary practice. Within the constraints of their business models - in which small- to medium-sized vendors largely confined to cities compete with opportunistic itinerant traders - they are able to use certain strategies to build a reputation for quality. Nonetheless, the largest burden of dealing with substandard drugs of any actor in the supply chain fell on the cattle owners.

\section{Cattle owners' strategies for mitigating drug quality issues}

In interviews and focus group discussions in Plateau State, many cattle owners said that ineffective treatments for trypanosomiasis were a major issue, with one group describing poor-quality trypanocides as the 'number one' (focus group in Maiyanga, Plateau State, 29 April 2014) veterinary health problem they faced. The Fulani discussed here are agro-pastoralists - though despite cultivating crops as well as keeping cattle, their livelihoods were closely tied to the well being of their livestock. One group reported that they commonly bought drugs from a small vendor in a nearby village, or from mobile traders who travel daily to different markets that are held on a particular day of the week, or simply sell them by the side of the road. Many distributors and veterinarians were especially suspicious of the ethics of these traders:

\section{'on the street, you see people with small baskets selling drugs. These drugs have expired most of the time, this man is taking his basket with drugs and just selling them like they are bread.' (interview with an experienced practicing veterinarian, Zaria, 25 \\ April 2014)}

Cattle owners reported that these trypanocides brought mixed results. Compounding the problem was that it took several weeks for the effectiveness of a particular dose to become apparent. This meant that when a drug seemed to fail, by the time a customer returned to the point of sale to complain, the particular batch of drugs at a shop or the trader in question at a market had either moved on or only worked on a particular day.

Whereas other work has emphasised the importance of correctly gauging dosages based on animal weight (Machila et al. 2008), the cattle owners in Plateau State said they had not adopted this practice. Instead, they administered a fixed dosage of $10 \mathrm{ml}$ per adult animal (or $5 \mathrm{ml}$ for a calf less than two years old). Although a non-standard approach, this seems a logical response: if drug quality is frequently variable, why bother dosing precisely?

To the dismay of the veterinarian who assisted me with this discussion group, the cattle owners also reported another non-standard practice: the simultaneous use of multiple trypanocide products from different product classes ${ }^{\mathrm{h}}$. Although in some cases, use of two different drugs (known as a 'sanative pair', see Bouyer et al. 2013) is recommended by veterinarians as a strategy against drugresistant strains of trypanosomiasis, it is not usually prescribed as a first-line treatment option. Again, however, if a cattle owner suspects that some of the drugs he has purchased are ineffective, but has no way to be sure, a 'belt and braces' approach of using the drugs together becomes a potentially logical, albeit a risky one.

The key strategies, however, were the use of drugs in small quantities and experimentation. The cattle owners had adopted a practice of testing a drug on a small number of sick animals first and then waiting to see the result before buying more of the same product. It was accepted, however, that this information would never be perfect. As one member of the Fulani cattle owners explained, with broad agreement from his peers: 
'If you can see [the trypanocide] is working, you will go back to the shop and buy more of the same kind. But even that one, it might be different or expired. You are just guessing.' (focus group in Maiyanga, Plateau State, 29 April 2014)

That much livestock treatment is now carried out by people without formal veterinary training is an issue that has attracted much attention in recent decades (e.g. McCorkle and Mathias-Mundy 1992; Leonard 1993). Some African governments and non-governmental organisations have encouraged the use of 'paravets' or 'livestock auxiliaries' (Catley et al. 2004): professionals trained with intermediate levels of knowledge, whilst others have documented extensive forms of informal or 'local' veterinary knowledge (e.g. Beinart and Brown 2013). Many veterinarians in Nigeria and elsewhere, however, remain suspicious of or even hostile towards such schemes, arguing that an overreliance on partially trained staff brings serious risks for animals and livelihoods.

The predominance of lay veterinary practices amongst the Fulani in this study highlights two important issues. Firstly, the incorrect administration of drugs can produce the same form of treatment failure as the use of fake or substandard drugs. Secondly, it demonstrates active innovation and experimentation on the part of cattle owners to find veterinary health solutions in the absence of formal, trained support, an issue to which I shall return.

I asked why they did not travel to Jos - the nearest city, around 90 min away by road - to buy drugs from a larger retailer, where prices were likely to be cheaper and quality more assured. Such communities are hardly isolated, not least because many commercial drivers are themselves Fulani ${ }^{i}$. This topic led to further discussion about the difficulties of collective action:

'You can give someone money to buy some small things for you, but even if you know that [person] very well, they may just run away with the money. And what of the shop in Jos? They can decide to cheat you as well.' (interview with a Fulani cattle owner, following focus group in Maiyanga, Plateau State, 29 April 2014)

Others mentioned that reluctance to pool cash made other long-distance purchases - for instance, building equipment - more difficult and expensive.

In summary, the cattle owners interviewed demonstrated acute awareness of drug quality issues and had developed a number of innovative strategies to address the problem, most of which involved using small-scale transaction and experimentation to mitigate risk. However, potentially effective collective action tended to be stymied by a lack of trust between cattle owners and others, and between cattle owners themselves. Furthermore, some of their dosing practices are alarmingly similar to those that have encouraged drug resistance in other settings (Melaku and Birasa 2013: 87). I now turn to consider the structural market features that engender this behaviour.

\section{Markets, authenticity and weak states}

Trade in other forms of fake and counterfeit products such as electronics and clothing - has tended to emphasise the performativity involved: for instance, in selling products as genuine or the seeking out of products (such as designer bags) that are sufficiently impressive facsimiles to confer status to the owner (e.g. Nakassis 2012; Geiger-Oneto et al. 2013). The visual properties of luxury goods mean that the products themselves broadcast their authenticity (or, at least, their proximity as a copy). In contrast, drugs are silent: inscrutable in uniform packaging and tablets, powders and liquids whose potencies are uncertain without expensive equipment.

The different actors described here read the packaging differently in some ways: for instance, national and regional distributors said that customers should look carefully at the packaging to check expiry dates and the like, whereas wary cattle owners pointed out that such packaging could easily be switched or falsified. All agreed, however, that it was often extremely difficult to reliably identify counterfeit products, and all but impossible to identify incorrectly stored ones.

With the inscrutability of the products themselves, and the lack of a state authority able to reliably act as an arbiter of authenticity, actors in the supply chain are left with few options. An understanding of these options can be informed by examining coping strategies in other similar low-trust environments. In particular, Marcel Fafchamps (2004) offers a useful framework for interpreting several processes at work in this study. In particular, the emergence of forms of assurance between vendors - such as the form of interpersonal ties - is possible without a state or professional body, albeit with increased transaction costs:

\section{'a certain level of economic efficiency in trade can be achieved through purely private, decentralised and informal means.' (Fafchamps 2004: 170)}

Fafchamps also notes the relative scarcity of large companies, retailers and chains in many African markets, a relevant observation for this study as small-scale retailers predominate in the veterinary drug sector. For example, of 15 shops visited in Kano, Kaduna and Zaria, only 3 were part of a franchise or chain, the remaining 12 being small independently owned business. Only 1 of those 15 shops employed a qualified veterinarian to provide consultations 
and advice to customers. Most described their role purely as being retailers, rather than offering additional services. To use Fafchamps' distinction (2004: 9-15), the small scale and narrow role of such shops suggest that they are able to build trust, a bilateral tie between themselves and their customers. However, almost all retailers lacked the scale to build a public reputation that is, multilateral relationships with many customers and potential customers.

Cattle owners who had formed a relationship with a retailer felt more confident about the drugs they were buying, but acknowledged that there were still risks:

\section{'Whenever I come to [Kaduna] to visit I see the same Mallam ${ }^{j}$ at that shop because I know he is very honest - he will not give you the fake ones. But even he can be cheated without being aware - he could be given the expired [drugs] to sell and not even see [realise] it.' (interview with a Fulani cattle owner in Bokkos LGA, Plateau State, 29 April 2014)}

Conversely, one discussion group reported that their nearest drug vendor would sometimes sell apparently ineffective products. They might withdraw their custom temporarily, they said, but would usually patronise the shop again eventually, albeit to buy a different product. Thus, there are stark limitations on the usefulness of gathering of information, when such knowledge may quickly be found to be incorrect or out of date. This febrile, uncertain situation where even honest men could inadvertently sell poor-quality products or previously trusted acquaintances could decide to cheat meant that a constant strategy of risk avoidance was required. It would be a mistake, however, to characterise this marketplace purely in terms of its shortcomings.

Furthermore, whilst Nigeria's veterinary drug market has been largely unregulated for the past 25 years, the negative label 'unregulated' only describes what the market is not and says little about what it is. 'Unregulated' may imply a harmful 'Wild West', free-for-all or chaotic system. Yet the actions of both distributors and vendors bring a degree of order and certainty to this market. For instance, large-scale importers were well aware that many of the vendors they dealt with also traded cheaper, generic products from other distributors. One importer said that he had considered opening up and running directly his own shops in two major cities:

'I could do all [of this] myself, to take all of the profits. But actually, you know, that would be a very dangerous game - those ones who are my customers now would be my rivals, you understand, and all my eggs would be in one basket. Even if now, they are also dealing with crooks, they are still my customers.' (interview with a Fulani cattle owner in Bokkos LGA, Plateau State, 29 April 29 2014)

That is, instead of getting more directly involved in a marketplace filled with uncertain and problematic products, he chose to minimise his risks by keeping a certain distance. This cautious approach of sticking to known roles rather than attempting to expand ambitiously - mirrored by other actors further down the chain - is crucial: supply chains that are seldom vertically integrated are an important way of minimising risk.

In short, animal health care and veterinary markets have continued in this zone of state abandonment. As Majekodumni notes, the Nigerian middle belt now has 'generally lower levels of disease than in the past as well as increased access of herders to curative drugs' (2011: 160). When drugs are sold out of the back of a Toyota Starlet on cattle market day, vendors are meeting a need for affordable and locally available products. Thus, an economic system has emerged that offers a solution - however imperfect - to the much discussed 'last mile' problem that besets other rural health services (e.g. Bhutta 2011).

Liberal economists have argued that inefficient African states have been 'a millstone around otherwise efficient markets' (Mkandawire 2001: 293). Regardless of the broad applicability of this economic philosophy, it does appear that the lack of veterinary regulation since the 1980s has indeed produced a system with some innovative and efficient characteristics. Despite being low tech and obscure, perhaps the trading patterns and informal experimentation seen in cattle grazing areas of Nigeria parallel other innovations which have taken place in the absence of a strong state. For instance, East Africa's mPesa system of mobile banking has flourished, overtaking its equivalents in the West in part because it is unfettered by cumbersome and restrictive regulations (Atlantic 2014).

\section{Implications for interventions}

A nuanced assessment of veterinary marketplaces that accounts for the difficult circumstances in which they have emerged is an important precursor towards planned interventions. Participants in this supply chain may include not only unscrupulous criminals who squeeze out honest providers, but also imaginative suppliers responding to customers' demands and difficult circumstances with innovation and efficiency. Therefore, characterising and tackling the drug quality problem as a criminal enterprise with implied law enforcement solutions may not be the most appropriate framing.

NAFDAC's strategies in tackling substandard human drugs, commendable as they have been, have often tended towards dramatic spectacles of seizures and prosecutions. Should the new veterinary NAFDAC directorate be able 
to identify similarly criminal vendors in the veterinary sector, such an approach might have value. However, in the case of trypanocides, the cost of testing drugs is extremely high - around $€ 300$ per sample at Senegal (personal communication, Peter Jeffries, June 2014). Whilst the technical difficulties and cost of testing remains so high relative to the value of the drugs, surely, the regulatory ability to survey the market will remain limited.

Instead, an approach that emphasises training and engagement alongside enforcement might be profitable for NAFDAC and other relevant authorities. Indeed, certain features of the marketplace should be favourable for such efforts. For instance, the urban retailers visiting during the course are closely grouped together in specific areas of the marketplaces in Kaduna and Kano (and to a lesser extent Jos). Their proximity (and evident familiarity with one another) should make it relatively easy to convene for training. A workshop might include identifying substandard or expired products and offer advice on correct storage practices. Should the authorities be able to build such relationships, other activities such as compensated amnesties for expired products or intelligence sharing regarding sources of substandard projects might be possible and cost effective. Convening or visiting rural and itinerant retailers would admittedly require more effort and expense, but their locations are nonetheless generally well known.

Importantly, such broad interventions would cut across the mandates of multiple agencies and professions. As well as veterinarians (who, despite being scarce in rural areas, have the legal authority to prescribe and dispense drugs) and NAFDAC, research institutions like the Nigerian Institute for Trypanosomiasis and Onchocerciasis Research and the National Veterinary Research Institute are also important centres of expertise. Coordinating a multi-agency effort appropriately is a significant political challenge.

\section{Cultural disconnections and opportunities}

'The Fulani man is so sneaky in whatever he does. He has to trust you by some acts you have done to him to confirm that trust.' (interview with a senior veterinarian based at the Nigerian Veterinary Research Institute, 30 April 2014)

'There is also abuse of trypanocides by the Fulani because of ignorance.' (interview with a small drug vendor, Zaria, 24 April 2014)

Whilst many drug vendors are relatively accessible as targets for government or industry partnership, expanding engagements with cattle-owning communities would be a greater challenge. Aside from the broad geographical distribution and sheer size of such communities, cultural distance is also an issue. It is commonplace to hear urban
Nigerians describe the Fulani in condescending terms. I frequently heard such attitudes throughout the course of this project (and indeed during previous research). The main tropes for describing the Fulani are 'backwardness', 'uneducated', 'ignorant', 'stubborn' and, less commonly, their tendency towards violence ${ }^{k}$. Aside from the fact that such cultural stereotypes are often unfounded ${ }^{1}$, they reveal a certain level of unfamiliarity between the Fulani and urban professional and policy-making elites. Even in otherwise ethnically diverse Nigerian professional circles (especially in national bureaucracies which must pursue a 'federal character' of ethnic representativeness, see Mustapha 2007), pastoralist communities are often absent or scarce.

Work such as this illustrates that, far from being 'backward' or 'stubborn' in this area, many Fulani are in fact adaptable and innovative. Perhaps those in the government and industry would be able to better plan interventions if they were more aware of such strategies and perspectives. Pastoralist associations such as Miyetti Allah would seem to be well placed to facilitate this. More importantly still, cattle owners perceive the drug quality as a subset of the broader problem of treatment failure. Perhaps the fact that substandard drug problems are often confused with other sources of treatment failure might offer an opportunity for interventions, rather than an obstacle to them.

Perhaps government- or industry-supported training could address issues like diagnosis, injection procedures and dosing practices at the same time as advising on sourcing genuine products. Various schemes across Africa (e.g. Allport et al. 2005) have proposed that community animal health workers can provide some level of veterinary care in the absence of more formal, professionalised services. In the specific area of this study, schemes in the recent past offered short courses in veterinary training to pastoralists at the National Veterinary Research Institute in Vom. However, these have ceased in recent years because of ethnic-religious clashes in the region, with Vom seen as an unsafe area for Fulani at the time this fieldwork was carried out. Rebuilding the tenuous and frayed ties between pastoralists, veterinary professionals, the pharmaceutical industry and regulators should be an urgent priority.

The use of credit in relationship building between vendors and customers might also suggest another area of potential intervention. Perhaps a microcredit scheme of some sort could be used to incentivise the purchase of genuine products.

\section{Conclusion}

The issue of substandard drugs is often shrouded in confusion, frequently caused by competing definitions and conceptions of the problem. In the case of Nigerian trypanocides, most agree that fake and counterfeit products 
are a less serious threat than ubiquitous generic products whose efficacy and provenance are difficult to judge. The new attention paid to this problem by the regulator NAF$\mathrm{DAC}$ is a welcome development. However, the regulateand-enforce paradigm may not be entirely suitable in this industry - a lasting solution will require a more holistic understanding of and engagement with the problem. Both global and local actors involved in combatting substandard drugs should carefully consider the limits of 'hard' regulation and the potential benefits of other approaches.

Regulators should be guided not only by laboratory analyses of products, but also by a clear understanding of how drugs are bought, sold and used. Of particular importance are the already-existing informal mechanisms that have evolved independently of the state to mitigate the damage of substandard drugs. The informal drug market, therefore, is more than just a malfunctioning, chaotic deviation from a textbook ideal. The inscrutability of the drugs and the uncertain causes of treatment failure, however, drive a major flaw in these otherwise efficient supply chains and markets as they inhibit reputation building and the formation of trusting relationships. Regulators should concentrate their efforts in resolving these specific market failings, perhaps emphasising training-based strategies that would enable market participants to make more informed decisions.

Finally, one cannot ignore that the drug quality problem is in part a consequence of political and economic abandonment. The structural neglect of the livestock sector and pastoralist communities is an enduring characteristic of Nigerian society. It is a neglect that has allowed the withering of crucial animal health services as well as painfully slow responses to readily apparent problems. It is also a neglect that allows unhelpful misconceptions about the practices of cattle owners to solidify - fallacies that must be actively challenged. With momentum apparently now building to tackle the issue of substandard veterinary drugs in Nigeria, careful planning and research will be required to carry out interventions that start to unwind rather than perpetuate this neglect.

\section{Endnotes}

${ }^{a}$ Cattle in Nigeria are primarily owned by an ethnolinguistic group known as the Fulani in Hausa and English (though they themselves use the term 'Fulbe'), who practise various forms of pastoralism or agro-pastoralism. They are by no means the only owners of cattle or users of trypanocides, but given their dominance of the cattle sector, this paper emphasises their role as customers.

bhttp://www.who.int/medicines/services/counterfeit/ overview/en/.

'The 'rebasing' exercise of adjusting Nigeria's economic statistics which took place in April 2014 estimated the livestock sector as being worth $\$ 8.66$ billion in 2013 (National Bureau of Statistics 2014).

${ }^{\mathrm{d}}$ The researcher speaks basic Hausa but was assisted by staff at the Nigerian Institute for Trypanosomiasis and Onchocerciasis Research.

${ }^{\mathrm{e}}$ These insights emerged serendipitously during the course of the discussion. However, a more systematic approach to collecting an oral history of cattle owners and comparing it to insights from archival work would be an extremely valuable addition to our understanding of this period.

${ }^{\mathrm{f}} \mathrm{A}$ trypanocide containing the active ingredient homidium chloride.

${ }^{g}$ The Association published an open letter complaining of the 'Unjust and unfair exclusion of the Veterinary Profession in the Management of Affairs of the National Agency for Food, Drug Administration and Control' (The Nation, 13 July 2011).

${ }^{\mathrm{h}}$ There are four classes of trypanocide widely used in Nigeria: diminazene aceturate, homidium bromide, homidium chloride and isometamidium chloride. All are used curatively, and isometamidium chloride is also used prophylactically (Majekodunmi 2011: 13).

${ }^{\mathrm{i}}$ I am grateful to an anonymous reviewer for clarifications on this issue.

${ }^{j}$ Mallam is a Hausa honorific with a similar meaning to the French 'Monsieur'.

${ }^{\mathrm{k}}$ Of course, such mistrust may be mutual. Several Fulani pastoralists expressed doubts about the quality and good intentions of veterinarians: one Fulani retailer of veterinary drugs in Bokkos town (interview, 30 April 2014) described rumours that some Christian veterinarians might be deliberately trying to poison their cattle. Although the retailer said he did not believe such rumours himself, they nonetheless suggest a wider atmosphere of suspicion (see also Okello et al. 2014).

${ }^{\mathrm{l}}$ To choose just one example, Higazi (2013: 41) notes that although in most areas of Plateau State it is common for the children of Fulani pastoralists to have lower rates of school attendance and completion than other sedentary groups, there are a number of areas where these measures are higher, as the Fulani are in places relatively wealthy.

\section{Competing interests}

The author declares that he has no competing interests.

\section{Acknowledgements}

This work was funded as part of the European Research Council project 'Investigated Networks of Zoonosis Innovation'. I thank Shelby Grossman,

Ayodele Majekodunmi, Mohammed Mamman, Grant Napier, and James Smith, all of whom provided extremely useful feedback on drafts of this paper. Susan Welburn and Maura Reilly also provided valuable comments. During the course of this project, Professor Mamman and his staff at the Nigerian Institute for Trypanosomiasis and Onchocerciasis Research provided generous assistance and advice in planning and executing the fieldwork. I particularly thank Augustine Igweh, Charles Dongkum, and Ibrahim Bala, without whom this 
research would have not been possible. Finally, I thank an anonymous reviewer for their detailed and thoughtful comments. I take sole responsibility for the analysis presented herein, as well as any errors or omissions.

Received: 22 July 2014 Accepted: 21 November 2014 Published online: 31 January 2015

\section{References}

Adebayo, AG. 1995. Jangali: Fulani pastoralists and colonial taxation in Northern Nigeria. International Journal of African Historical Studies 28(1): 113-50.

Allport, R, R Mosha, M Bahari, E Swai, and A Catley. 2005. The use of communitybased animal health workers to strengthen disease surveillance systems in Tanzania. Revue Scientifique et Technique-Office international des épizooties 24(3): 921-32.

Almuzaini, T, I Choonara, and H Sammons. 2013. Substandard and counterfeit medicines: A systematic review of the literature. BMJ Open 3: e002923. doi:10.1136/bmjopen-2013- 002923.

Alubo, SO. 1994. Death for sale: A study of drug poisoning and deaths in Nigeria. Social Science \& Medicine 38(1): 97-103.

Atlantic. 2014. 'Africa's Tech Edge' by Dayo Olopade. http://www.theatlantic.com/ magazine/archive/2014/05/africas-tech-edge/359808/. Accessed 30 June 2014.

Babalobi, OO. 2007. Professional issues for the Nigerian veterinarian in the twenty first century. Nigerian Veterinary Journal 26(2): 1-7.

Beinart, W, and K Brown. 2013. African local knowledge and livestock health disease \& treatments in South Africa. Woolbridge: James Currey.

Bhutta, ZA. 2011. The last mile in global poliomyelitis eradication. The Lancet 378(9791): 549-52.

Bouyer, J, F Bouyer, M Donadeu, T Rowan, and G Napier. 2013. Community-and farmer-based management of animal African trypanosomosis in cattle. Trends in Parasitology 29(11): 519-22.

Budd, LT. 1999. DFID-funded tsetse and trypanosomiasis research and development since 1980 (V.2 Economic analysis). London: Department for International Development.

Burci, GL. 2013. Public health and 'counterfeit' medicines: The role of the World Health Organization. ASIL Insights 17(2)

Catley, A, T Leyland, JC Mariner, DMO Akabwai, B Admassu, W Asfaw, G Bekele, and HS Hassan. 2004. Para-veterinary professionals and the development of quality, self-sustaining community-based services. Revue Scientifique et Technique-Office international des épizooties 23(1): 225-52.

Chaka, H, T Eguale, D Lidetu, and D Gizaw. 2009. Evaluation of the efficacy of anthelmintics sold on Ethiopian markets against Haemonchus contortus in experimentally infected sheep. Tropical Animal Health and Production 41(6): 973-8.

Clift, Charles. 2010. Combating counterfeit, falsified and substandard medicines: Defining the way forward? Chatham House Briefing Paper, November 2010, GH BP 2010/01.

Cockburn, Robert, N Paul, EK Newton, Akunyili Dora Agyarko, and Nicholas J White. 2005. The global threat of counterfeit drugs: Why industry and governments must communicate the dangers. PLoS Medicine 2(4): e100.

Dégardin, K, Y Roggo, and P Margot. 2014. Understanding and fighting the medicine counterfeit market. Journal of Pharmaceutical and Biomedical Analysis 87: 167-75.

Dondorp, AM, PN Newton, M Mayxay, W Van Damme, FM Smithuis, S Yeung, A Petit, AJ Lynam, A Johnson, TT Hien, R McGready, JJ Farrar, S Looareesuwan, NP Day, MD Green, and NJ White. 2004. Fake antimalarials in Southeast Asia are a major impediment to malaria control: Multinational cross-sectional survey on the prevalence of fake antimalarials. Tropical Medicine \& International Health 9(12): 1241-6.

Erhun, WO, OO Babalola, and MO Erhun. 2001. Drug regulation and control in Nigeria: The challenge of counterfeit drugs. Journal of Health \& Population in Developing Countries 4(2): 23-34.

Fafchamps, Marcel. 2004. Market institutions in Sub-Saharan Africa: Theory and evidence. Cambridge: MIT Press

FAO. 2012. Alliance to combat black market in counterfeit veterinary drugs. http:// www.fao.org/news/story/en/item/123165/icode/. Accessed 10 June 2014.

Fernandez, FM, MD Green, and PN Newton. 2008. Prevalence and detection of counterfeit pharmaceuticals: A mini review. Industrial \& Engineering Chemistry Research 47(3): 585-90.

Gberindyer, FA, PA Onyeyili, and JA Bosha. 2014. Quality control properties of some brands of veterinary albendazole boluses common in Nigeria. Journal of Pharmacy and Pharmacology 2: 135-9.
Geerts, S, PH Holmes, MC Eisler, and O Diall. 2001. African bovine trypanosomiasis: The problem of drug resistance. Trends in Parasitology 17(1): 25-8.

Geiger-Oneto, Stephanie, D Betsy, Doug Walker Gelb, and James D Hess. 2013. "Buying status" by choosing or rejecting luxury brands and their counterfeits. Journal of the Academy of Marketing Science 41(3): 357-72.

Grasswitz, TR, TJ Leyland, JT Musiime, SJ Owens, and KR Sones (eds.). 2004. The veterinary pharmaceutical industry in Africa: A study of Kenya, Uganda and South Africa. Nairobi: African Union/Interafrican Bureau for Animal Resources (AU/IBAR).

Harper, I, N Rawal, and M Subedi. 2011. Disputing distribution: Ethics and pharmaceutical regulation in Nepal. Studies in Nepali History and Society 16(1): 1-40.

Higazi, Adam. 2013. Rural insecurity on the Jos Plateau, Nigeria: Livelihoods, land, and religious reform among the Berom, Fulani, and Hausa. Nigeria Research Network (NRN) Working Paper: University of Oxford.

Kané, M. 2008. Legislation, registration and control procedures for veterinary medicinal products in Western Africa. Paper presented at the OIE Conference on Veterinary Medicinal Products in Africa, Dakar, 25-27 March 2008.

Kingsley, P. 2014. NGOs, doctors, and the patrimonial state-tactics for political engagement in Nigeria. Critical African Studies 6(1): 6-21.

Leonard, DK. 1993. Structural reform of the veterinary profession in Africa and the New Institutional Economics. Development and Change 24(2): 227-67.

Lyons, M. 2002. The colonial disease: A social history of sleeping sickness in northern Zaire, 1900-1940. Cambridge: Cambridge University Press.

Machila, N, EM Fèvre, I Maudlin, and MC Eisler. 2008. Farmer estimation of live bodyweight of cattle: Implications for veterinary drug dosing in East Africa. Preventive Veterinary Medicine 87(3): 394-403.

Majekodunmi A. 2011. Pastoral livelihoods and the epidemiology of emergent trypanosomiasis on the Jos Plateau, Nigeria. PhD Thesis. The University of Edinburgh.

McCorkle, CM, and E Mathias-Mundy. 1992. Ethnoveterinary medicine in Africa. Africa 62(01): 59-93.

McPeak, JG, PD Little, and CR Doss. 2011. Risk and social change in an African rural economy: Livelihoods in pastoralist communities. London: Routledge.

Melaku, Achenef, and Bekele Birasa. 2013. Drugs and drug resistance in African animal trypanosomosis: A review. European Journal of Applied Sciences 5(3): 84-91.

Mkandawire, T. 2001. Thinking about developmental states in Africa. Cambridge Journal of Economics 25(3): 289-314.

Mustapha, Abdul Raufu. 2007. Institutionalising ethnic representation: How effective is the Federal Character Commission in Nigeria? Centre for Research on Inequality, Human Security and Ethnicity, Working Paper No.43.

Nakassis, CV. 2012. Counterfeiting what?: Aesthetics of brandedness and BRAND in Tamil Nadu, India. Anthropological Quarterly 85(3): 701-21.

National Bureau of Statistics. 2014. Measuring better: Presentation of preliminary results of the rebased nominal gross domestic product (GDP) estimates for Nigeria 2010 to 2013, delivered by the Statistician-General of the Federation \& Chief Executive Officer. Abuja: National Bureau of Statistics, Dr. Yemi Kale.

Newton, Paul N, Abdinasir A Amin, Bird Chris, Passmore Phillip, Dukes Graham, Tomson Göran, Simons Bright, Bate Roger, Philippe J Guerin, and Nicholas J White. 2011. The primacy of public health considerations in defining poor quality medicines. PLoS Medicine 8(12): e1001139.shuk.

Okello, AL, AO Majekodunmi, A Malala, SC Welburn, and J Smith. 2014. Identifying motivators for state-pastoralist dialogue: Exploring the relationships between livestock services, self-organisation and conflict in Nigeria's pastoralist Fulani. Pastoralism 4(1): 1-14.

Raufu, A. 2006. Nigeria leads fight against "killer" counterfeit drugs. Bulletin of the World Health Organization 84(9): 685-764.

Seear, M, D Gandhi, R Carr, A Dayal, D Raghavan, and N Sharma. 2011. The need for better data about counterfeit drugs in developing countries: A proposed standard research methodology tested in Chennai, India. Journal of Clinical Pharmacy and Therapeutics 36(4): 488-95.

Shukla, N, and T Sangal. 2009. Generic drug industry in India: The counterfeit spin. Journal of Intellectual Property Rights 14(3): 236-40.

Teko-Agbo, A, F Messomo Ndjana, L Walbadet, K Akoda, ELH Niang, and FA Abiola. 2008. Quality of veterinary medicinal products in circulation in Cameroon and Senegal. Paper presented at the OIE Conference on Veterinary Medicinal Products in Africa, Dakar, 25-27 March 2008.

Thornton, PK, RL Kruska, N Henninger, PM Kristjanson, RS Reid, F Atieno, A Odero, and T Ndegwa. 2002. Mapping poverty and livestock in the developing world. Nairobi: ILRI. 
Tilley, H. 2004. Ecologies of complexity: Tropical environments, African trypanosomiasis, and the science of disease control in British Colonial Africa, 1900-1940. Osiris 19: 21-38.

van der Geest, Sjaak, Susan Reynolds Whyte, and Anita Hardon. 1996. The anthropology of pharmaceuticals: A biographical approach. Annual Review of Anthropology 25: 153-78.

van Ufford, Paul Quarles, and Fred Zaal. 2004. The transfer of trust: ethnicities as economic institutions in the livestock trade in West and East Africa. Africa 74(2): 121-45

Van Wyk, JA, FS Malan, L Van Rensburg, PT Oberem, and MJ Allan. 1997. Quality control in generic anthelmintics: Is it adequate? Veterinary Parasitology 72(2): 157-65.

Waller, PJ, F Echevarria, C Eddi, S Maciel, A Nari, and JW Hansen. 1996. The prevalence of anthelmintic resistance in nematode parasites of sheep in southern Latin America: General overview. Veterinary Parasitology 62(3): 181-7

Wanyangu, SW, RK Bain, MK Rugutt, JM Nginyi, and JM Mugambi. 1996 Anthelmintic resistance amongst sheep and goats in Kenya. Preventive Veterinary Medicine 25(3): 285-90.

WHO. 2011. Substandard/spurious/falsely-labelled/falsified/counterfeit medical products - Report by the Director-General, 64th World Health Assembly A64/16. Provisional agenda item 13: 7.

Widner, Jennifer, and Alexander Mundt. 1998. Researching social capital in Africa. Africa 68(1): 1-24

Zak, Paul J, and Stephen Knack. 2001. Trust and growth. The Economic Journal 111(470): 295-321.

Submit your manuscript to a SpringerOpen ${ }^{\circ}$ journal and benefit from:

- Convenient online submission

- Rigorous peer review

- Immediate publication on acceptance

- Open access: articles freely available online

- High visibility within the field

- Retaining the copyright to your article

Submit your next manuscript at $>$ springeropen.com 